\title{
Comparative Evaluation of Single, Bilateral Intra- Testicular Injection of Hypertonic Saline Solution and Calcium Chloride as Chemical Sterilizing Agents in Male Cats
}

\author{
Misbah Ijaz' ${ }^{1}$, Rizwan Abdul Aleem ${ }^{1}$, Asad Manzoor ${ }^{1}$, Anas Sarwar Qureshi' ${ }^{2 *}$, Faiza Hassan ${ }^{3}$, \\ M Tahir Mohy ud Din ${ }^{1}$, Zia Mohy ud Din ${ }^{1}$, Khizar Hayyat ${ }^{2}$, Rubi Tabassum ${ }^{4}$ \\ ${ }^{1}$ Department of Clinical Medicine and Surgery, Faculty of Veterinary Science, UAF
}

${ }^{2}$ Department of Anatomy, Faculty of Veterinary Science, UAF

${ }^{3}$ Institute of Physiology, Pharmacology and Pharmacy, Faculty of Veterinary Science, UAF

${ }^{4}$ Livestock and Dairy Development Department, Pakistan

*Corresponding author: Anas Sarwar Qureshi, Department of Anatomy, Faculty of Veterinary Science, UAF

\begin{tabular}{|c|c|}
\hline ARTICLE INFO & ABSTRACT \\
\hline Received: 慧 September 11, 2019 & Citation: Misbah Ijaz, Rizwan Abdul Aleem, Asad Manzoor, Anas Sarwar Qureshi, Faiza \\
\hline Published: 幽 September 17, 2019 & $\begin{array}{l}\text { Hassan, et al., Comparative Evaluation of Single, Bilateral Intra-Testicular Injection of } \\
\text { Hypertonic Saline Solution and Calcium Chloride as Chemical Sterilizing Agents in Male } \\
\text { Cats. Biomed J Sci \& Tech Res 21(3)-2019. BJSTR. MS.ID.003598. }\end{array}$ \\
\hline
\end{tabular}

\section{Introduction}

Homeless cats and dogs pose a major threat for the spreading of zoonotic diseases around the globe. 27 million cats and dogs are bounded annually in United States alone. In 1990, it was predicted that in United States 5.7 to 9.5 million cats and 5.4 to 9.1 million dogs were euthanatized in animal houses. To maintain the pet population, sterilization is expressed as the most adequate method. Sterilization is an approach that impairs the testicular tissues by various chemicals, causing damage and atrophy of the testicular cells by deducing or stopping the blood delivery or their surgically excision [1]. Neutering of male animals is more significant than female counterparts since males have greater capability of producing offspring as compared to females [2]. In addition to the fore-mentioned primary objective, sterilization is also used for the eradication of the secondary sex characteristics of animal like urine marking, mounting and aggressive behavior towards other males [3]. With evolving research, scientists have deduced that myths like lethargy of neutered toms or urethral obstruction has no relation with neutering instead these complications are mainly related to dietary plan of the animal and urinary tract disorders [3]. It is generally perceived that un-owned and free roaming cats suffer more parasitism and diseases and have short span of life as compared to owned cats. Therefore, to deduce the population of such un-owned cats is a worthwhile goal.

Various techniques of sterilization are being practiced which include hormonal, surgical, mechanical and chemical sterilization [4]. Castration by chemical agents is a nonsurgical approach for the male sterilization [5]. It has been practiced by injecting some necrotic toxic agent into the testicles in animals belonging to different families like Felidae, Canidae, Rodentia etc. The chemicals which are being utilized for sterilization are, calcium chloride, formalin, zinc gluconate + arginine, hypertonic saline solution, potassium permanganate, chlorhexidinegluconate + cetrimide, glycerol, ethanol, sodium fluoride [6,7] while concentrated sodium chloride was used by [8]. Administration of these chemical agents into the epididymidis, testes and ductus deference ultimately lead perpetual azoospermia, reduce testosterone production and alteration in physical structure of testes. It also causes a reduction in the androgen production and improves the androgen-dependent disorders such as prostatic disease, gonadal disease and behavioral problem (mounting, aggression, urine marking). The injection of 
these chemicals sterilants into the epididymis, testicles, or ductus deferens induces sterility by damaging sperm cells transportation and producing fibrous occlusions that cause azoospermia. The intratesticular injection leads to testicular necrosis and decreases the spermatogenesis as well as reduction in the serum concentration of testosterone [3]. Therefore, the chemical approach of castration is considered as a suitable alternate of surgical method. It is less time consuming and demands less technical staff also. Moreover, it is convenient for practice and no extra post-operative care is required [9]. Hypertonic saline solution (HSS) has not yet been evaluated for chemical castration in male cats. Therefore, the current study was planned with the objective to evaluate and compare the efficacy of hypertonic saline solution (HSS) with calcium chloride as chemosterilizing agent in male cats.

\section{Materials and Methods}

\section{Experimental Animals and Treatment Protocol}

Experimental animals ( $\mathrm{n}=20$ toms) were equally and randomly allocated to four groups containing five animals in each. The toms of group A and B were injected a single, bilateral, intra-testicular injection of hypertonic saline solution respectively at concentration of $20 \%$ and $30 \%$. Calcium chloride was administered in testes of animals of group C. While, in the D group, intra-testicular injection of sterilized normal saline solution was given, and this group was considered as a control group. The amount of testing solutions administered was according to the width of testes in each animal [10].

\section{Intra-Testicular Injection}

Before injection, the scrotum was shaved and cleaned with an antiseptic of povidone-iodine solution. Intra-testicular injection was given with a sterile 21-gauge needle. Needle was inserted from the caudoventral aspect of testis approximately $1 \mathrm{~cm}$ from the epididymal tail and directed towards the dorso-cranial aspect of that testis so that when needle is withdrawn from the proximal to distal end, the solution was uniformly administered throughout the entire route. Table 1 gives an estimate of the amount of solution to be injected with respect to the weight of the testes

Table 1: Volume of the solution to be injected into each testis based on testicular width.

\begin{tabular}{|c|c|}
\hline Testis width $(\mathbf{m m})$ & Volume/testis $(\mathbf{m l})$ \\
\hline $10-12$ & 0.2 \\
\hline $13-15$ & 0.3 \\
\hline $16-18$ & 0.5 \\
\hline $19-21$ & 0.7 \\
\hline $22-24$ & 0.8 \\
\hline $25-27$ & 1.0 \\
\hline
\end{tabular}

\section{Evaluation Criteria}

Clinical Assessment: Alterations in scrotum (e.g. pain, swelling, dermatitis) were noted once daily for 3 days and afterwards once a week until the completion of the experiment. Vernier's calipers were used to measure width of the testes post injection with the same time interval as described above [11].

Serum Testosterone Concentration Analysis: Blood was obtained in Gel vaccutainers from the cephalic vein and was centrifuged @2000 rpm for 15 minutes to separate serum. Serum was preserved at $-20^{\circ} \mathrm{C}$ until the completion of the experiment. Competitive ELISA was done using commercially available AccuBind ${ }^{\circledR}$ ELISA Microwells Testosterone Kit [12-15].

Histological Examination: After the removal of testes, samples were washed with normal saline and fixed in Bouin's fixative solution in $50 \mathrm{ml}$ plastic containers for each right and left testis, separately [16]. Conventional tissue processing of the samples was done. Tissue sections with thickness $5 \mu \mathrm{m}$ were cut with the help of rotary microtome and mounted afterwards on the glass slides. Slides were then stained with Hematoxylin and Eosin stain and its histological features were compared with the help of Image $₫$ Software.

\section{Statistical Analysis}

Data thus generated were analyzed by Generalized Linear Model Complete randomized design (CRD-2 factor) and difference in means was compared by Least Significance Difference (LSD) at $5 \%$ level of significance $[17,18]$.

\section{Results}

\section{Testis Width}

Regarding testicular width a statistically non-significant ( $p>0.05$ ) difference was observed in all the groups at start of the study period. Administration of trial drugs resulted in significant $(\mathrm{p}<0.05)$ increase in terms of testicular width at day $3^{\text {rd }}$ post injection. At this sampling time point all the four groups were statistically non-significant $(\mathrm{p}>0.05)$ among each other. At $1^{\text {st }}$ week post injection, a statistically non-significant $(p>0.05)$ decrease in testicular width was observed in all the groups than previous sampling time point. A further decrease in testicular width was observed in groups $A, B$ and $C$ at $2^{\text {nd }}$ week post injection where group $C$ was statistically significant $(\mathrm{p}<0.05)$ from previous sampling time point (Table 2). At 3rd week post injection a significant $(\mathrm{p}<0.05)$ decrease in testicular width in groups B and C was observed. At 4 th week post injection there was non-significant $(p>0.05)$ decrease in testicular width of animals of group $D$ whereas there was a significant $(\mathrm{p}<0.05)$ decrease in testicular width in groups $A, B$ and $\mathrm{C}$ where group B was the lowest (Figure 1). 


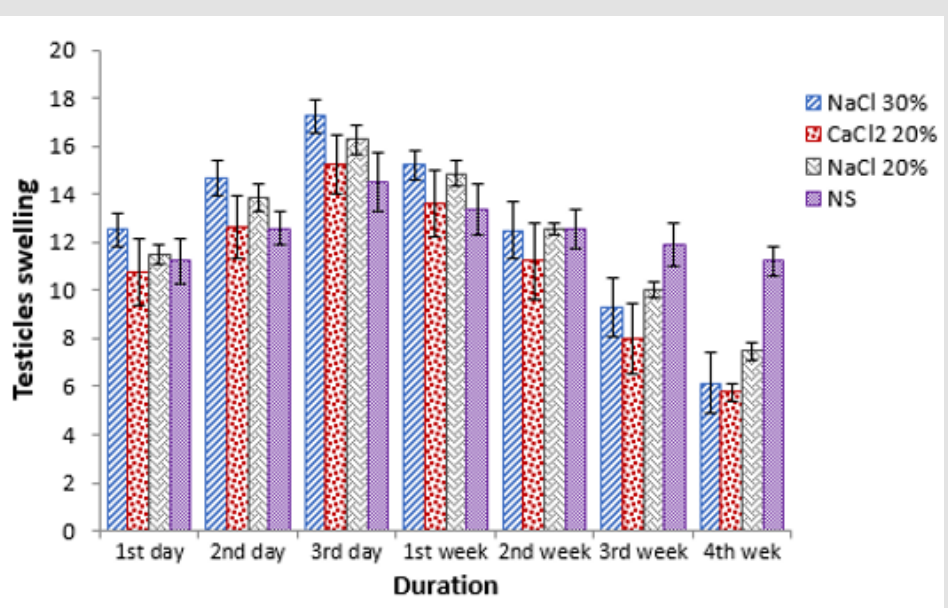

Figure 1: Comparison of testis width of four groups at different time intervals.

Table 2: Testis width (mm; Means \pm SE) at different time intervals of four groups viz bilateral intra testicular injection of $20 \%$ HSS (Group A), 30\% HSS (Group B), 20\% $\mathrm{CaCl}_{2}$ (Group C) and normal saline solution (Group D).

\begin{tabular}{|c|c|c|c|c|c|}
\hline \multirow{2}{*}{ Duration } & \multicolumn{4}{|c|}{ Treatment } & \multirow{2}{*}{ Mean } \\
\hline & $\mathrm{NaCl} 20 \%$ & $\mathrm{NaCl} 30 \%$ & $\mathrm{CaCl}_{2} 20 \%$ & NS & \\
\hline $1^{\text {st }}$ day & $11.49 \pm 1.39 b-f$ & $12.51 \pm 0.96 a-f$ & $10.75 \pm 0.43 c-h$ & $11.22 \pm 0.69 b-g$ & $11.49 \pm 0.45 \mathrm{CD}$ \\
\hline $2^{\text {nd }}$ day & $13.83 \pm 1.30 \mathrm{a}-\mathrm{e}$ & $14.66 \pm 0.72 \mathrm{a}-\mathrm{d}$ & $12.60 \pm 0.59 \mathrm{a}-\mathrm{f}$ & $12.58 \pm 0.71 \mathrm{a}-\mathrm{f}$ & $13.42 \pm 0.45 \mathrm{BC}$ \\
\hline $3^{\text {rd day }}$ & $16.28 \pm 1.22 \mathrm{ab}$ & $17.27 \pm 1.20 \mathrm{a}$ & $15.20 \pm 0.63 \mathrm{abc}$ & $14.52 \pm 0.69 \mathrm{a}-\mathrm{d}$ & $15.82 \pm 0.51 \mathrm{~A}$ \\
\hline $1^{\text {st }}$ Week & $14.86 \pm 1.38 \mathrm{a}-\mathrm{d}$ & $15.21 \pm 1.03 \mathrm{abc}$ & $13.59 \pm 0.51 \mathrm{a}-\mathrm{e}$ & $13.37 \pm 0.63 a-e$ & $14.26 \pm 0.47 \mathrm{AB}$ \\
\hline $2^{\text {nd }}$ Week & $12.57 \pm 1.57 \mathrm{a}-\mathrm{f}$ & $12.51 \pm 0.83 \mathrm{a}-\mathrm{f}$ & $11.22 \pm 0.25 \mathrm{~b}-\mathrm{g}$ & $12.54 \pm 1.20 \mathrm{a}-\mathrm{f}$ & $12.21 \pm 0.51 \mathrm{C}$ \\
\hline $3^{\text {rd }}$ Week & $10.05 \pm 1.50 \mathrm{~d}-\mathrm{h}$ & $9.30 \pm 0.90 \mathrm{e}-\mathrm{h}$ & $8.00 \pm 0.32 \mathrm{fgh}$ & $11.91 \pm 1.20 \mathrm{~b}-\mathrm{f}$ & $9.81 \pm 0.59 \mathrm{D}$ \\
\hline $4^{\text {th }}$ Week & $7.49 \pm 0.40 \mathrm{fgh}$ & $6.15 \pm 0.63 \mathrm{gh}$ & $5.75 \pm 0.37 \mathrm{~h}$ & $11.22 \pm 1.25 \mathrm{~b}-\mathrm{g}$ & $7.65 \pm 0.60 \mathrm{E}$ \\
\hline Mean & $12.37 \pm 0.65 \mathrm{~A}$ & $12.51 \pm 0.68 \mathrm{~A}$ & $11.01 \pm 0.54 \mathrm{~B}$ & $12.48 \pm 0.38 \mathrm{~A}$ & \\
\hline
\end{tabular}

\section{Histo-pathological Examination}

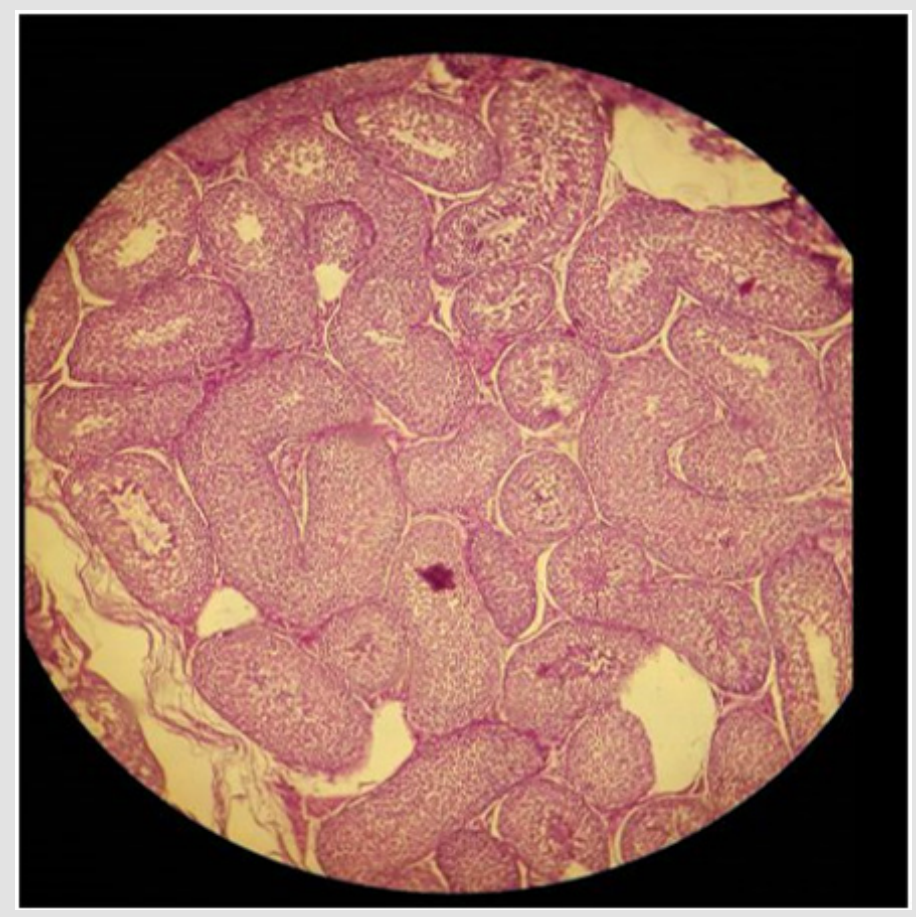

Plate 1: Effect of normal saline solution (NSS) on (a) testicular parenchyma and (b) seminiferous tubules in sexually adult male cats; intact seminiferous tubules and normal testicular paranchyma can be noted. H\&E; $400 \mathrm{X}$. 
Histo-pathological results exposed that HSS efficaciously impaired testicular parenchyma and lead to necrotic changes in testicular tissue in commensuration with calcium chloride. In normal saline solution treated group mild to negligible necrotic changes were noticed. Increasing concentration of HSS produced unalterable necrotic changes. Bilateral intratesticular administration of $20 \%$ concentration of HSS produced partially to complete necrotic changes in the tissues of testicles. Epithelium of seminiferous tubules was moderately destroyed together with alteration in order of parenchyma cells. Moderate coagulated necrosis and vacuolization of Interstitial and Sertoli cells was noticed including pyknosis of nuclei (Plates 1 \& 2). $30 \%$ concentration of HSS produced acute necrosis in tissues of testicles. Acute necrosis and degeneration of seminiferous tubules was noticed. Interstitial cells and Sertoli cells were also severely degenerated along with disruption of parenchyma cells. Germ cells were diminished from seminiferous tubules. Empty lumen was noticed in seminiferous tubules (Plate 3). Bilateral intratesticular administration of $20 \%$ concentration of calcium chloride produced severe necrosis in tissues of testicles. Acute necrosis and degeneration of seminiferous tubules was noticed. Sertoli cells and interstitial cells were also severely degenerated along with disruption of parenchyma cells. Germ cells were diminished from seminiferous tubules. Empty lumen was noticed in seminiferous tubules (Plate 4). Intra-testicular injection of $20 \%$ and $30 \%$ hypertonic saline solution induced destruction of interstitial cells and seminiferous tubules which leads to atrophy of testicles. The $30 \%$ concentration of hypertonic saline induced necrosis compared to $20 \%$ calcium chloride.

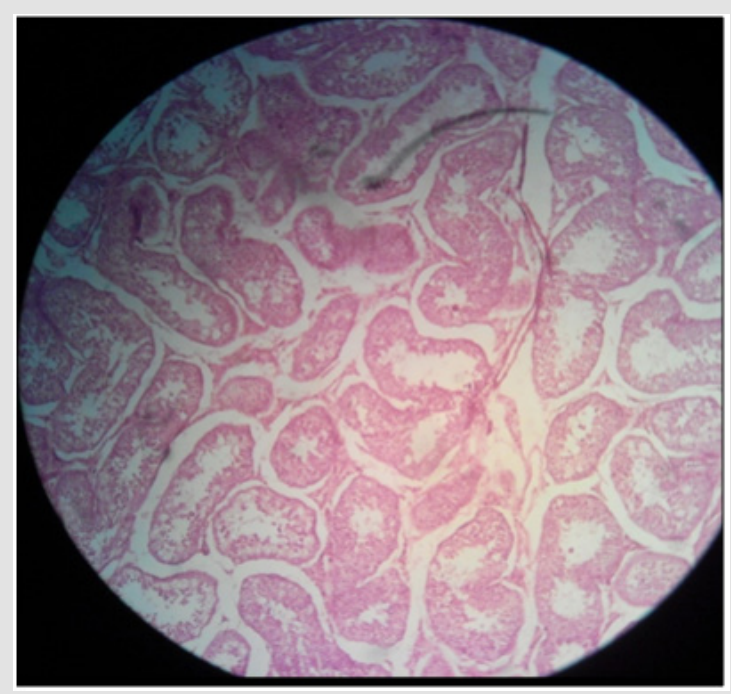

Plate 2: Effect of $20 \%$ HSS on the seminiferous tubular epithelium of testis in sexually adult male cats; (a) disintegration of germinal epithelium and germ cell associations along with (b) diminishing of germ cells from the seminiferous tubules can be noted. H\&E; X400.

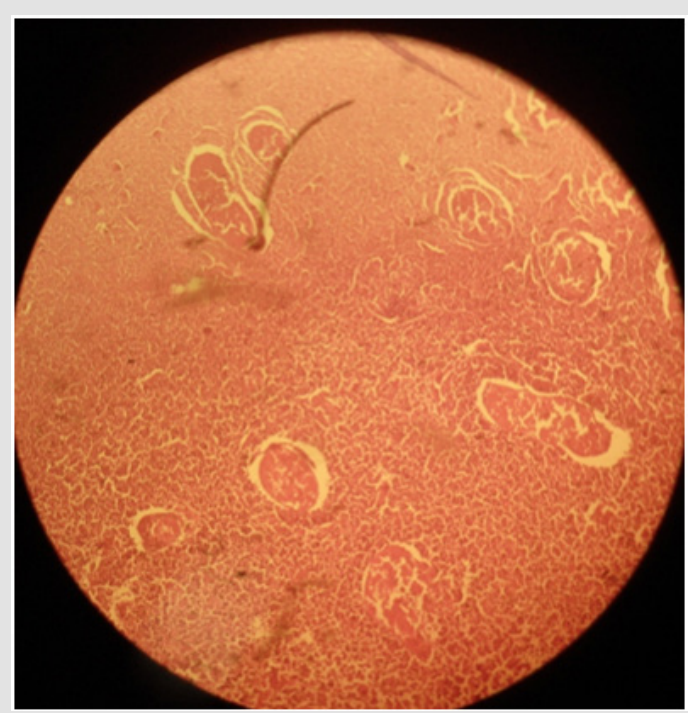

Plate 3: Effect of $30 \%$ hypertonic saline solution (HSS) on testicular parenchyma and seminiferous tubules in sexually adult male cats; (a) coagulative necrosis of seminiferous tubules and Leydig cells and (b) severe disorganization of parenchyma cells along with (c) diminishing of germ cells from the seminiferous tubules can be noted. H\&E; $400 \mathrm{X}$. 


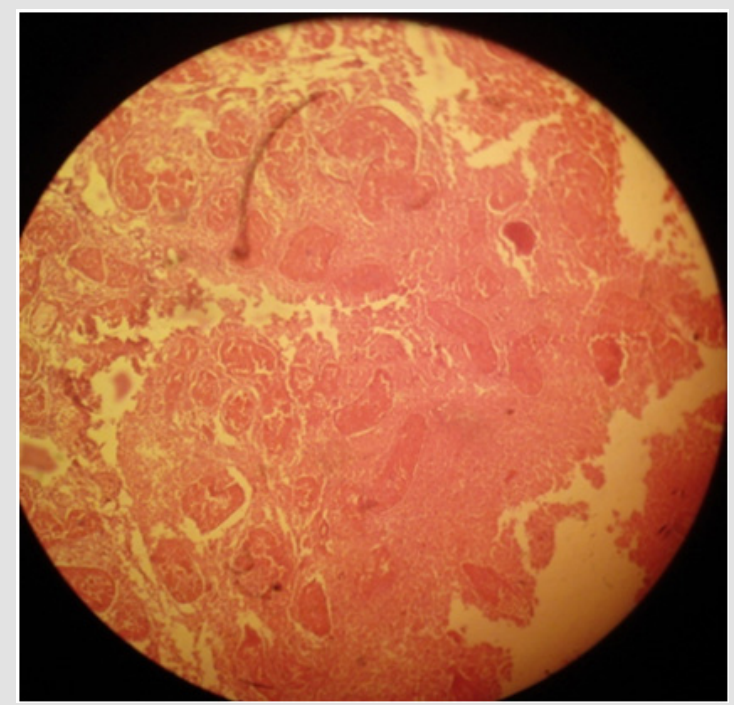

Plate 4: Effect of $20 \%$ calcium chloride $\left(\mathrm{CaCl}_{2}\right)$ on testicular parenchyma and seminiferous tubules in sexually adult male cats; (a) coagulative necrosis of seminiferous tubules and Leydig cells and (b) severe disorganization of parenchyma cells along with (c) diminishing of germ cells from the seminiferous tubules can be noted. H\&E; $400 \mathrm{X}$.

\section{Serum Testosterone Concentration}

At baseline animals of groups, A and D had a statistically significant $(\mathrm{p}<0.05)$ lower testosterone as compared to animals of group B and C. At $3^{\text {rd }}$ day post injection a significant $(\mathrm{p}<0.05)$ decrease in testosterone level was observed where group D was statistically higher as compared to all other groups. At one-week post treatment a further decrease in testosterone level of groups A, B and C was observed whereas an increase in testosterone level of animals of group D was observed, this change in both ways was significantly $(\mathrm{p}<0.05)$ different from previous study intervals. At 2nd week post treatment a statistically non-significant ( $p>0.05$ ) difference in terms of serum testosterone level was observed among all the groups. At $3^{\text {rd }}$ week post treatment statistically significant $(p<0.05)$ decrease in serum testosterone level of animals of groups $\mathrm{B}$ and $\mathrm{C}$ was observed whereas there was statistically nonsignificant ( $p>0.05$ ) change in serum testosterone level of animals of group B and D (Table 3). A similar trend was observed in serum testosterone level of all the groups at $4^{\text {th }}$ week post treatment where group B was lowest and group D was highest (Figure 2).

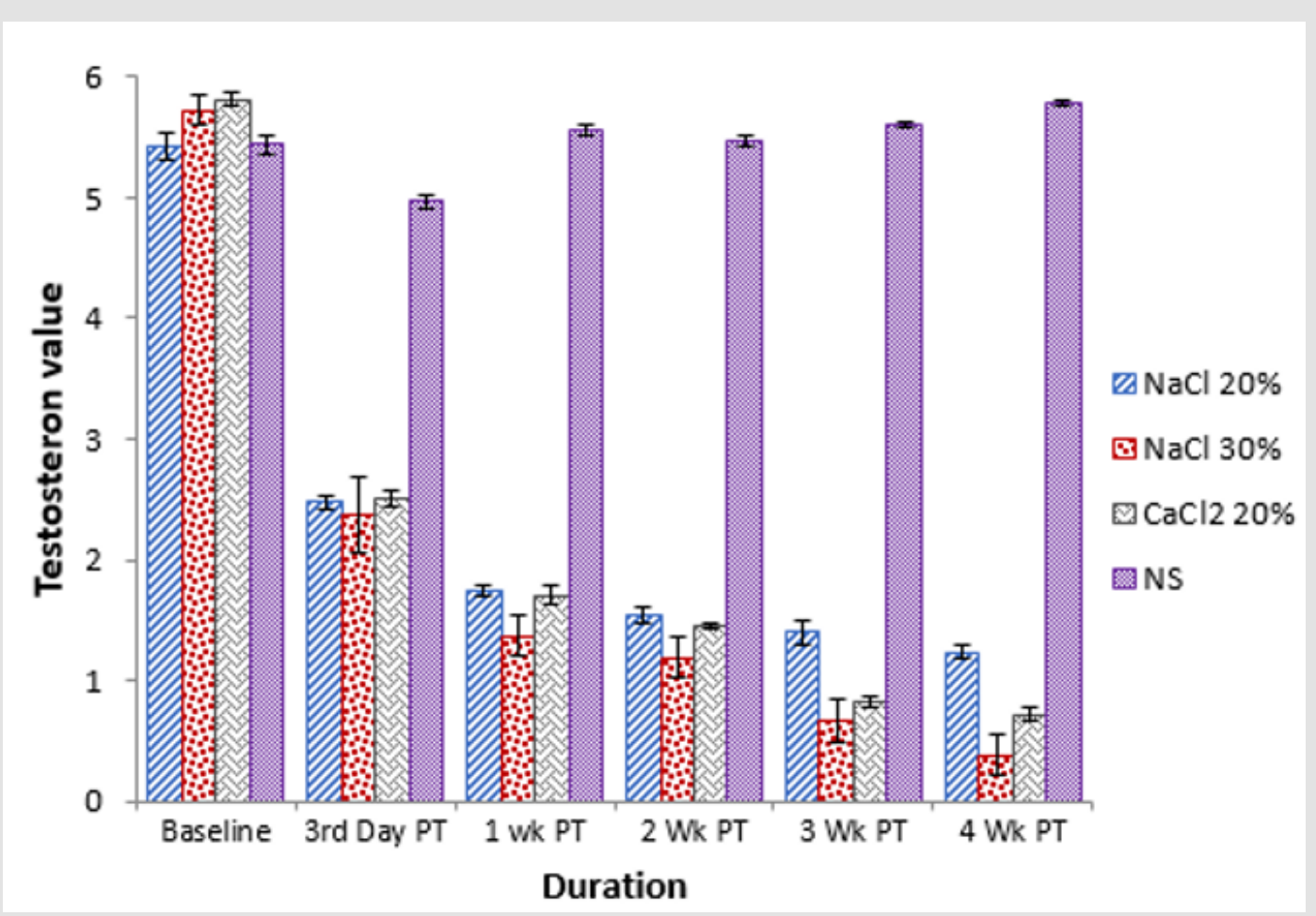

Figure 2: Comparison of the testosterone concentration of four groups at different time intervals. 
Table 3: Serum testosterone concentration (ng/ml; Means $\pm \mathrm{SE}$ ) at different time intervals of four groups viz bilateral intratesticular injection of 20 HSS (Group A), 30\% HSS (Group B) $\mathrm{CaCl}_{2}$ (Group C) and normal saline solution (Group D).

\begin{tabular}{|c|c|c|c|c|c|}
\hline \multirow{2}{*}{ Duration } & \multicolumn{4}{|c|}{ Treatment } & Mean \\
\cline { 2 - 6 } & NaCl 20\% & NaCl 30\% & CaCl2 20\% & $5.44 \pm 0.11 \mathrm{ab}$ & $5.60 \pm 0.06 \mathrm{~A}$ \\
\hline Baseline & $5.43 \pm 0.12 \mathrm{ab}$ & $5.72 \pm 0.07 \mathrm{a}$ & $5.81 \pm 0.06 \mathrm{a}$ & $4.97 \pm 0.06 \mathrm{~b}$ & $3.08 \pm 0.26 \mathrm{~B}$ \\
\hline $3^{\text {rd }}$ Day PT & $2.47 \pm 0.32 \mathrm{c}$ & $2.38 \pm 0.05 \mathrm{c}$ & $2.50 \pm 0.06 \mathrm{c}$ & $5.56 \pm 0.05 \mathrm{a}$ & $2.59 \pm 0.40 \mathrm{C}$ \\
\hline $1^{\text {st }}$ Week PT & $1.74 \pm 0.16 \mathrm{~d}$ & $1.37 \pm 0.04 \mathrm{de}$ & $1.71 \pm 0.07 \mathrm{~d}$ & $5.47 \pm 0.07 \mathrm{ab}$ & $2.41 \pm 0.41 \mathrm{C}$ \\
\hline $2^{\text {nd }}$ Week PT & $1.54 \pm 0.16 \mathrm{~d}$ & $1.19 \pm 0.05 \mathrm{def}$ & $1.45 \pm 0.03 \mathrm{~d}$ & $5.61 \pm 0.09 \mathrm{a}$ & $2.12 \pm 0.47 \mathrm{D}$ \\
\hline $3^{\text {rd }}$ Week PT & $1.40 \pm 0.18 \mathrm{de}$ & $0.67 \pm 0.02 \mathrm{fg}$ & $0.82 \pm 0.05 \mathrm{efg}$ & $5.78 \pm 0.06 \mathrm{a}$ & $2.03 \pm 0.50 \mathrm{D}$ \\
\hline $4^{\text {th }}$ Week PT & $1.23 \pm 0.16 \mathrm{def}$ & $0.38 \pm 0.02 \mathrm{~g}$ & $0.72 \pm 0.05 \mathrm{fg}$ & $5.47 \pm 0.05 \mathrm{~A}$ & \\
\hline Mean & $2.30 \pm 0.28 \mathrm{~B}$ & $1.95 \pm 0.33 \mathrm{C}$ & $2.17 \pm 0.32 \mathrm{~B}$ & \\
\hline
\end{tabular}

\section{Discussion}

Chemical sterilization is a bloodless and non-surgical technique for male sterilization. Chemical technique of sterilization is much cheaper, less demanding and is feasible for colossal population control programs in both cats and dogs. Intra-testicular administration of sterilant induces deterioration and necrosis of parenchyma cells of testicles. Whereas intra-epididymal administrations cause fibrous occlusion and cause destruction of transportation of sperm cells and induces azoospermia. Various sterilizing agents such as formalin, zinc acetate + arginine, chlorhexidine gluconate + cetrimide, glycerol, ethanol, sodium fluoride, potassium permanganate and calcium chloride has been utilized for this objective [19]. Effectiveness of single, bilateral intra-testicular administration of solution of hypertonic saline in different concentrations as a chemo-sterilizing agent and comparison with calcium chloride in male cats was evaluated in the present study. It was achieved by performing clinical estimation (testicular size), concentration of serum testosterone and histopathological investigation. Orchiectomy was performed at the end of study for histo-pathological examination. The findings of present experiment revealed that intra-testicular injection of hypertonic saline solution and calcium chloride induced testicular deterioration and necrosis along with reduction in concentration of serum testosterone. These findings agree with experiment of Emir et al., 2008 who recorded analogous results in rats by injecting $20 \%$ HSS. Due to the necrosis and degeneration of testicular cells, spermatogenesis is stopped, and destruction of interstitial cells is the probable cause of reduction in testosterone production.

Similar results were described by Jana and Samanta. Plasma concentration of testosterone decreased due to necrotic properties of calcium chloride when injected intra-testicular in cats. Furthermore, the necrosis of testosterone secreting interstitial cells also participated in reduction of concentration of testosterone in blood [20]. Abshenas reported that concentration of serum testosterone was reduced considerably with administration of Eugenia caryophyllata essential oil when it was injected intratesticular. Considering the size of testicles, our study showed a considerable reduction in testicular width in comparison to control group at the completion of experimental duration after a rapid increase in size in 24-48 hours with a gradual decrease after chemical administration. These results are much like Leoci who described that bilateral intra-testicular administration of sterilizing solution calcium chloride produced a considerable decrease in testicular width after a short time of mild swelling. Testicular deterioration and destruction consequently lead to atrophy after a certain duration of time. Similar results were also reported by Oliveria who reported similar results with bilateral intra-testicular administration of sterilized zinc gluconate solution. A sound correlation was noted between testosterone hormone concentration and age. They concluded that testosterone hormone concentration is not dependent on testicular size. Our results demonstrated that both the testicular size and testosterone concentration were reduced with the extension of time.

Regarding histo-pathological examinations the current experiment disclosed that testicles injected with hypertonic saline and calcium chloride exhibited destructive alterations in parenchyma cells of testicles. In seminiferous tubules, fibrosis was induced accompanying destructive alterations in germinal epithelium and coagulative necrosis of Sertoli cells and interstitial cells. These results agree with Neto who described that intratesticular administration of concentrated sodium chloride induces destructive alterations in testicles which led to fibrosis and necrosis. High concentration of $\mathrm{HSS}$ and $\mathrm{CaCl}_{2}$ cause atrophy and scar tissue formation in seminiferous tubules. Level of degeneration of spermatids, spermatocytes and increases rapidly with increase in concentration of the sterilant. An analogous experiment was conducted by Oliveria who concluded that intratesticular administration of zinc base solution in male cats induced proliferation of polymorphonuclear leucocytes and other blood cells in seminiferous tubules. Our results are also supported by the findings of Cavalieri who revealed that zinc acetate solution produced obvious destructive alterations in the tissues of testicles in bull calves. These alterations lead to testicular atrophy and ultimately infertility.

\section{Conclusion}

The findings of the study lead to a conclusion that HSS have potential to replace other (physical or surgical) methods in practice 
to neutralize the male cats. It has been proved to be less time taking, less painful but equally effective.

\section{References}

1. Abshenas J, MM Molaei, A Derakhshnfar, N Ghalekhani (2013) Chemical sterilization by intratesticular injection of Eugenia caryophyllata essential oil in dog: a histopathological study. Ir J Vet Surg 8(19): 9-16.

2. Benjamin MM (1978) Outline of Veterinary Clinical Pathology. In Benjamin MM (Eds.), (2nd Ed.) Thelowa state university press, Ames, Iowa, USA.

3. Bloomberg MS (1996) Surgical neutering and non-surgical alternatives. J Am Vet Med. Assoc 208: 517-519.

4. Cavalieri J, M Wang, L Johnson (2015) Chemical sterilization of Bos indicus bull calves following intratesticular injection of zinc acetate: Effects on semen quality and testicular changes. Anim Reprod Sci 156: 23-33.

5. Currah JM, SH Hendrick, JM Stooley (2009) The behavioral assessment and alleviation of pain associated with castration in beef calves treated with fluxin meglumine and caudal lidocaine epidural anesthesia with epinephrine. Can Vet J 50(4): 375-382.

6. Emir L, M Dadalı, M Sunay, D Erol, M Çaydere, et al. (2008) Chemical castration with intratesticular injection of $20 \%$ hypertonic saline: A minimally invasive method. Urol Oncol Seminars and Original Investigations 26(4): 392-396.

7. Fagundes AKF, ECS Oliveira, BM Tenorio, CCS Melo, LTB Nery, et al. (2014) Injection of a chemical castration agent, zinc gluconate, into the testes of cat's results in the impairment of spermatogenesis: A potentially contraceptive approach for this species. Theriogenology 81(2): 230-236.

8. Hansen BD (2003) Assessment of pain in dogs: Veterinary clinical studies. Inst. Lab. Anim. Res J 44(3): 197-205.

9. Jana K, D Ghosh, PK Samanta (2005) Evaluation of single intratesticular injection of calcium chloride for non-surgical sterilization of male goats (Capra hircus): a dose dependent study. Anim Reprod Sci 86(1-2): 89108.

ISSN: 2574-1241

DOI: 10.26717/BJSTR.2019.21.003598

Anas Sarwar Qureshi. Biomed J Sci \& Tech Res

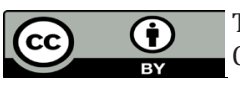

This work is licensed under Creative Commons Attribution 4.0 License

Submission Link: https://biomedres.us/submit-manuscript.php
10. Jana K, PK Samanta (2011) Clinical evaluation of non-surgical sterilization of male cats with single intra-testicular injection of calcium chloride. BMC Veterinary Research 7: 39.

11. Kutzler M, Wood A (2006) Non-surgical methods of contraception and sterilization. Theriogenoly 66(3): 524-525.

12. Kwak BK, S Lee (2013) Intratesticular injection of hypertonic saline: non-invasive alternative method for animal castration model. Dev Repord 17(4): 435-440

13. Lecoi R, G Aiudi, F Silvestre, E Lissner, G Lacalandra (2014) A dosefinding, long term study on the use of calcium chloride in saline solution as a method of non-surgical sterilization in dogs: Evaluation of the most effective concentration with the lowest risk. Acta Vet Scand 56: 62-68.

14. Neto OA, BG Gasperin, MT Rovani, GF llha, JE Nobrega, et al. (2014) Intratesticular hypertonic sodium chloride solution treatment as a method of chemical castration in cattle. Theriogenology 82(7): 10071011.

15. Oliveira ECS, MRP Moura, MJC Desa, VA Silva, JP Kastelic (2012) Permanent contraception of dogs induced with intratesticular injection of a Zinc Gluconate-based solution. Theriogenology 77(6): 1056-1063.

16. Rajkumar D (2013) Minimization of pain in cattle castration with respect to method, age and pain relief. Aust Vet J 55(6): 263-264.

17. Soto FRM, WG Viana, AJ Sousa, SR Pinheiro, GB Mucciolo (2007) Evaluation of zinc gluconate, either associated or not to dimethyl sulfoxide, as contraceptive method for male dogs. J Anim Repord 4: 119124.

18. Steel RGD, JH Torrie (2004) Principles and procedures of statistics. McGraw Hill Book Co. Inc. New York, USA.

19. Vanderstichel R, MJ Forzán, GE Pérez, JA Serpell, E Garde (2015) Changes in blood testosterone concentrations after surgical and chemical sterilization of male free-roaming dogs in southern Chile. Theriogenology 83(6): 1021-1027.

20.Wang M (2004) Neutersol intratesticular injection induces sterility in dogs and cats. In second international symposium by ACC\&D on nonsurgical contraceptive control in cats and dogs 165-169.

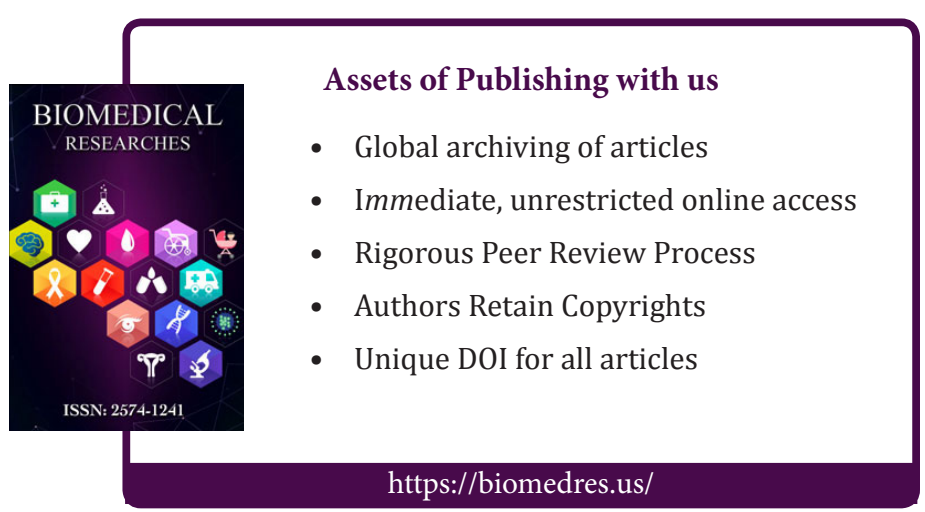

